Article

\title{
Design, Fabrication, and Evaluation of Polyglycolic Acid Modules with Canals as Tissue Elements in Cellular-Assembly Technology
}

\author{
Jingyuan Ji ${ }^{1,2,+}$, Yuan Pang ${ }^{1,2, *, \dagger}$, Stephanie Sutoko ${ }^{3}$, Yohei Horimoto ${ }^{4}$, Wei Sun ${ }^{1,2,5}$, \\ Toshiki Niino $^{3}$ and Yasuyuki Sakai ${ }^{6}$ \\ 1 Biomanufacturing Center, Department of Mechanical Engineering, Tsinghua University, Haidian District, \\ Beijing 100084, China; jijy18@mails.tsinghua.edu.cn (J.J.); weisun@mail.tsinghua.edu.cn (W.S.) \\ 2 Biomanufacturing and Rapid Forming Technology Key Laboratory of Beijing, Beijing 100084, China \\ 3 Institute of Industrial Science, University of Tokyo, Komaba 4-6-1, Meguro-ku, Tokyo 153-8505, Japan; \\ stephanie.sutoko@gmail.com (S.S.); niino@iis.u-tokyo.ac.jp (T.N.) \\ 4 Graduate School of Engineering, Shibaura Institute of Technology, Shibaura 3-9-14, Minato-ku, \\ Tokyo 108-8548, Japan; batty_mk2@me.com \\ 5 Department of Mechanical Engineering and Mechanics, College of Engineering, Drexel University, 3141 \\ Chestnut Street, Philadelphia, PA 19104, USA \\ 6 Department of Chemical System Engineering, Graduate School of Engineering, University of Tokyo, Hongo \\ 7-3-1, Bunkyo-ku, Tokyo 113-033, Japan; sakaiyasu@chemsys.t.u-tokyo.ac.jp \\ * Correspondence: pangyuan31@tsinghua.edu.cn; Tel.: +86-0106-277-2009; Fax: +86-0106-279-8112 \\ + Contributed equally to this work as co-first authors.
}

Received: 18 April 2020; Accepted: 25 May 2020; Published: 28 May 2020

check for updates

\begin{abstract}
The aim of the present study was to design and fabricate polyglycolic acid (PGA) modules on the basis of the Raschig ring as a tissue element for bottom-top tissue engineering to increase the feasibility of cellular-assembly technology. Three types of modules, namely, cylindrical, Raschig ring, and transverse-pore modules, with different numbers and orientations of canals, were designed and fabricated by modified selective-laser-sintering (SLS) technology. These modules maintained their structure in a flowing culture environment, and degradation did not create an acidic environment, hence promoting their ability to scale up to highly functional tissue. The modules were seeded with human hepatoma Hep G2 cells and cultured for 10 days. The transverse-pore modules were found to have the highest glucose consumption, albumin production, and cell viability among the three tested modules. Our study showed that the proposed module design provided better mass transfer and possessed the required mechanical strength to enable use in the construction of large tissue.
\end{abstract}

Keywords: modular assembly; polyglycolic acid; selective laser sintering; tissue engineering; hepatoma Hep G2 cells

\section{Introduction}

The bottom-up tissue-engineering (TE) approach for the construction of implantable tissue of clinically relevant size relies on the paradigm of assembling building blocks that mimic native functional units into large tissue constructs. This addresses two of the main limitations in the top-down TE approach: (1) maintenance of mass transfer, i.e., the diffusion of nutrients and waste removal; and (2) fabrication of a controlled and functional histoarchitecture [1,2]. With respect to the building blocks, cell spheroids, which are spherical microtissue assembled from monodispersed cells, are currently attracting considerable interest owing to their proximity to natural structures, cellular density, and organ-specific functions at a high level [3-6]. However, the hurdles posed by 
these cellular elements become significant when scaling up towards construction of larger tissue. The first factor is the strength of the cellular elements, since it is difficult to maintain their structure, especially in perfusion-culture environments. Furthermore, cells seeded onto the internal sides of cellular elements may gradually die after assembly. This is due to the restriction of diffusion of oxygen, nutrients, and metabolic waste products beyond a thickness of $100-200 \mu \mathrm{m}$ without the ingrowth of vasculature [7-9]. Hiroshi Mizumoto used a polyurethane foam (PUF)/spheroid culture to differentiate embryonic stem (ES) cells of hepatic lineage, and cells spontaneously formed spherical multicellular aggregates (spheroids) in the pores of the PUF. However, cell number decreased after 15 days of culture [10]. We worked on spacing tissue elements with the inclusion of poly (l, l-lactide) (PLLA) fibers in cellular aggregates, which partly improved local mass transfer for cultured cells, but was still limited by aggregate disintegration during a prolonged period of perfusion culture [11]. Hence, the dual goals of identifying cellular elements of a well-designed hierarchic structure to promote culture-medium distribution, and developing greater mechanical strength to sustain under dynamic-flow conditions, are yet to be attained.

The methodology of scaffold-based element construction, which is contrary to pure cell-based elements, is not merely to seed cells homogeneously onto a macroscopic, cell-instructive scaffold, but also to pattern the units of one tissue according to a predefined organization that guides the maturation of the TE construct towards a functional histoarchitecture, owing in part to the promotion of cellular self-sorting and self-assembly capabilities, and morphogenetic mechanisms [12,13]. Several studies showed that the morphogenetic mechanism of the adhesion-guided self-assembly of cells can be harnessed in TE to obtain an anisotropic structure from isotropic aggregates made up of multiple cell types [14-17]. Scaffolds have been subject to prolific research and development over the last thirty years and, in general, offer the advantage of optimal biocompatibility, cell attachment, and proliferation, while providing the biological, chemical, and mechanical cues to guide eventual cell differentiation and assembly into a 3D tissue construct. Scaffold-based tissue engineering has led to significant advancements in the reconstruction of various tissue types and organs, and, in some cases, has been translated into clinical practice [18-20]. Submillimeter-sized cylindrical modules of collagen were seeded with cells and then randomly assembled inside a perfusion chamber to form a macroscopic tissue construct called an "organoid" [21-24]. The radius of each module was defined according to the diffusion limit of nutrients to avoid cell starvation in the absence of vascularization. Although the above-mentioned studies elucidated a promising approach, module contraction and deformation cannot be avoided during perfusion culture.

In the present study, scaffold-based cell constructs were used as cellular tissue elements. It was essential that the elements were well-designed to overcome mass transfer limitation in in vitro tissue culture, with the material possessing good mechanical strength to sustain the structure under dynamic-flow conditions with acceptable shape deformation. In our study, to achieve these requirements, a cellular module was constructed on the basis of Raschig ring design. The Raschig ring is a tube design, with approximately equal length and diameter, extensively used as packed beds within columns for distillation and other chemical-engineering processes. They are favored for providing a large surface area within the volume of the column for interaction between liquid and gas or vapor [25]. Thus, the module for cellular-tissue-element construction based on the Raschig ring was expected to possess optimal mass transfer during cell culture to eliminate cell death due to the reasons mentioned above. To further investigate the effect of the hollow structure on mass transfer, three types of modules (cylindrical, Raschig ring, and transverse-pore), with canals of different numbers and directions, were designed. The modules were fabricated by selective-laser-sintering (SLS) technology, due to its advantage in forming complex-shaped surfaces of high porosity by the sintered particles [26]. SLS also does not need toxic chemical components and extra supporting structures for the modules with canals, making SLS the best option for this study [27]. Polyglycolic acid (PGA) powder was used in this research because of its ideal cell affinity, workability, proper degradation rate, and mature clinical application [28,29]. The deformation of modules made of PGA was observed in a 
dynamic environment to verify whether the design would address the vulnerability of the cellular elements. Human hepatoma Hep G2 cells were cultured in the modules. Cell attachment, viability, and function were evaluated to assess the potential of the cell-loaded PGA modules for use as cellular tissue elements in large tissue construction.

\section{Materials and Methods}

\subsection{Module Design and Fabrication}

The Raschig ring modules were designed on the basis of the Raschig ring structure. They were cylindrical with a hollow canal to promote mass transfer by sufficient contact with the culture medium. To achieve further mass transportation, transverse-pore modules with an additional canal on the side wall were also designed. The concept of a transverse-pore module was sketched using a computer-assisted-design (CAD) software program (Solidworks 2018, Dassault, Paris, France). The dimensions of the module were set as follows: $1000 \mu \mathrm{m}$ in height, $500 \mu \mathrm{m}$ in hollow diameter, and $1100 \mu \mathrm{m}$ in outer diameter (Figure 1a). The immobilized cells in the above-mentioned modules simultaneously had access to oxygen and nutrient supply from both the outer surface of the module and the canal. The additional canal on the side wall allowed unimpeded flow between different modules, thereby reducing the force on individual modules, especially under a dynamic-flow condition as illustrated in Figure 1b. Cylindrical modules without hollow canals served as controls.
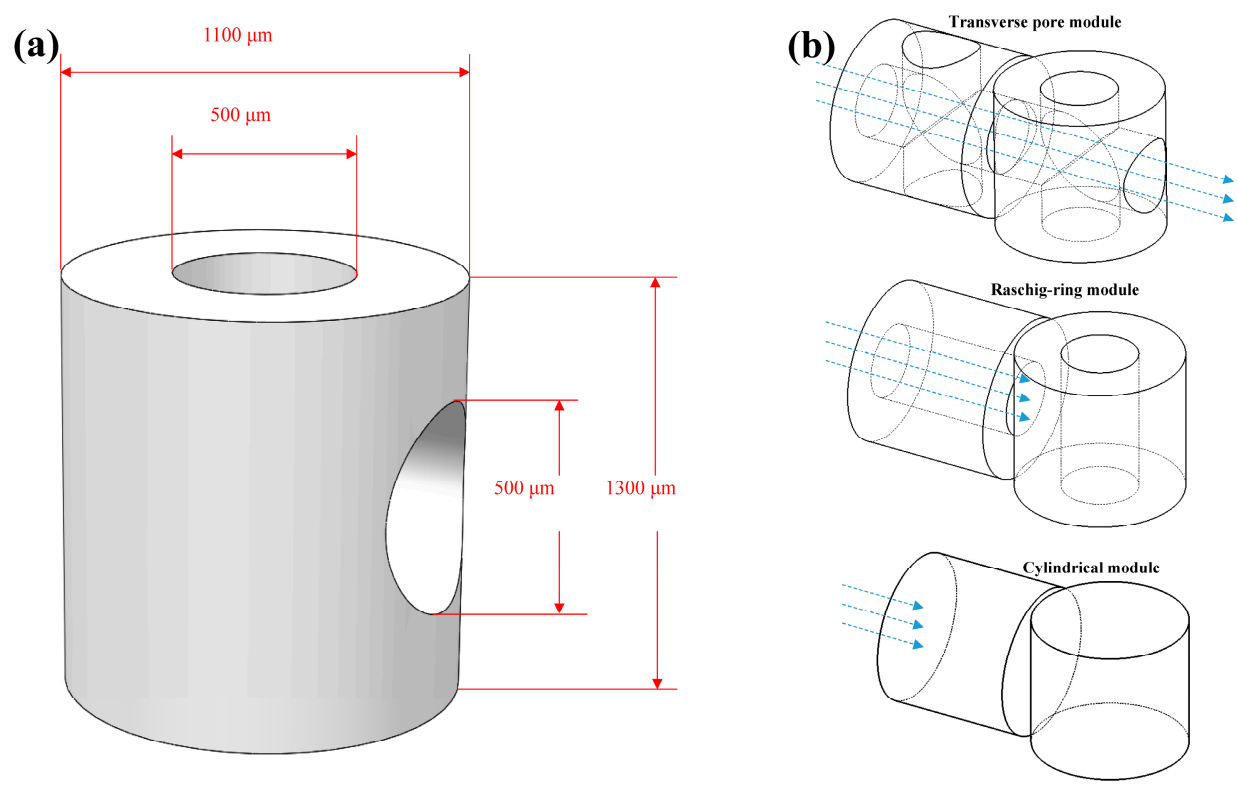

Figure 1. (a) Design and dimension of polyglycolic acid (PGA) modules. (b) Transverse-pore, Raschig ring, and cylindrical modules under dynamic-flow conditions.

PGA $\left(1.5 \times 10^{5}\right.$ M.W., Daicel, Japan) powder with a mean diameter of $50 \mu \mathrm{m}$ was selected as the raw polymer material. The density of raw polymer material was $1.5 \mathrm{~g} / \mathrm{cm}^{3}$, and energy density $55.6 \mathrm{~kJ} / \mathrm{mm}^{2}$. Modified SLS technology was used to fabricate the modules. In conventional SLS, the preheating process requires a high-energy electrical source and a long processing period. Due to the preheating process, it was difficult to restart the process if it was interrupted by problems such as computer crashes and recycle materials. Therefore, this study modified the SLS technology by canceling the preheating process to fabricate modules with the advantage of energy reduction, time reduction and a high percentage of material recycling. Before module fabrication, a series of rectangular layers of varying thicknesses were designed to optimize fabrication parameters (Figure 2a). The sintering process was accomplished by a $\mathrm{CO}_{2}$ laser with a scan peed of $1530 \mathrm{~mm} / \mathrm{s}$, during which the minimal 
scanning space was $20 \mu \mathrm{m}$, and maximal powder bed temperature was $200{ }^{\circ} \mathrm{C}$. Laser power was carefully selected to achieve the highest porosity of modules.
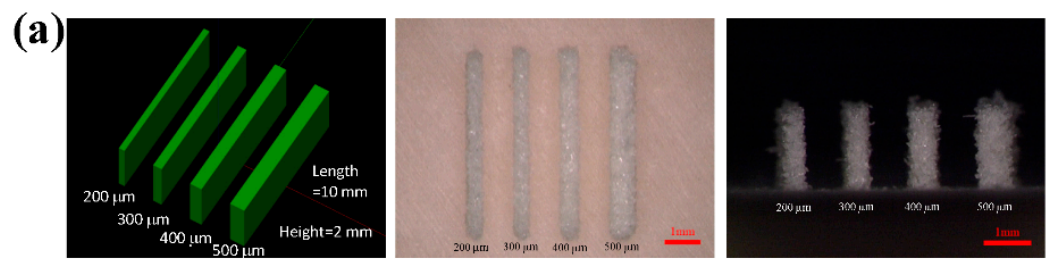

(b)
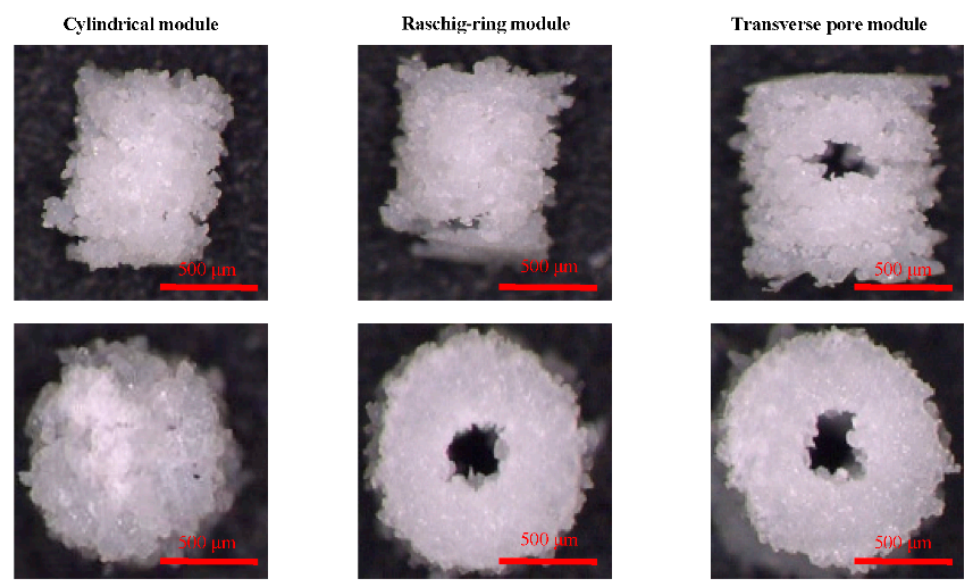

Figure 2. (a) Rectangular layers of varying thicknesses. (b) Three types of modules fabricated with PGA powder using modified selective-laser-sintering (SLS) technology.

\subsection{PGA Module Characterization}

The microstructures of sintered PGA modules were evaluated by microscopy. The porosity (p) of the module was determined using the following equation:

$$
\mathrm{p}=1-\frac{d}{d_{0}}
$$

where $d_{0}$ is the density of PGA powder and $d$ is the density of the fabricated module, calculated by its mass and volume $(d=m / v)$ [30].

The biodegradability of PGA was investigated for its suitability in tissue-element construction. Both PGA powder and fabricated modules were soaked in culture medium composed of high-glucose Dulbecco's Modified Eagle Medium (DMEM) supplemented with 10\% fetal bovine serum (FBS), $20 \mathrm{mM}$ 2-[4-(2-hydroxyethyl)piperazin-1-yl] ethanesulfonic acid (HEPES), 1\% nonessential amino acid solution (NEAA), and antibiotics. The culture medium was not changed for 10 days. The PGA powder and modules were observed during this period to detect morphological changes. Meanwhile, the $\mathrm{pH}$ of the culture medium was measured to evaluate the influence on cell culture caused by the biodegradation of the PGA material.

\subsection{Cell Inoculation and Culture}

Cells were inoculated into the PGA modules following the procedures shown in Figure 3a. Briefly, the sintered PGA modules were initially sterilized by $70 \%$ ethanol and UV exposure for $30 \mathrm{~min}$. Following this, the collected modules were resuspended in $1 \mathrm{~mL}$ of culture medium. To offer better cell attachment, a Collagen Gel Culturing Kit (Nitta Gelatin, Osaka, Japan) was used for surface treatment on modules. Briefly, Cellmatrix Type I-A (Nitta Gelatin, Osaka, Japan) was reconstituted by adding 10× culture medium and reconstitution buffer according to the manufacturer's instructions [31]. Reconstituted collagen gel $(1.0 \mathrm{~mL})$ was added to the module suspension with gentle pipetting (final 
concentration of collagen: $1.2 \mathrm{mg} / \mathrm{mL}$ ). The module suspension (with collagen gel added) was incubated at $4{ }^{\circ} \mathrm{C}$ for $1 \mathrm{~h}$ and then washed twice by adding $10 \mathrm{~mL}$ cold DMEM culture medium. The modules were finally collected by centrifugation at $40 \times g$ for $60 \mathrm{~s}$ before usage.

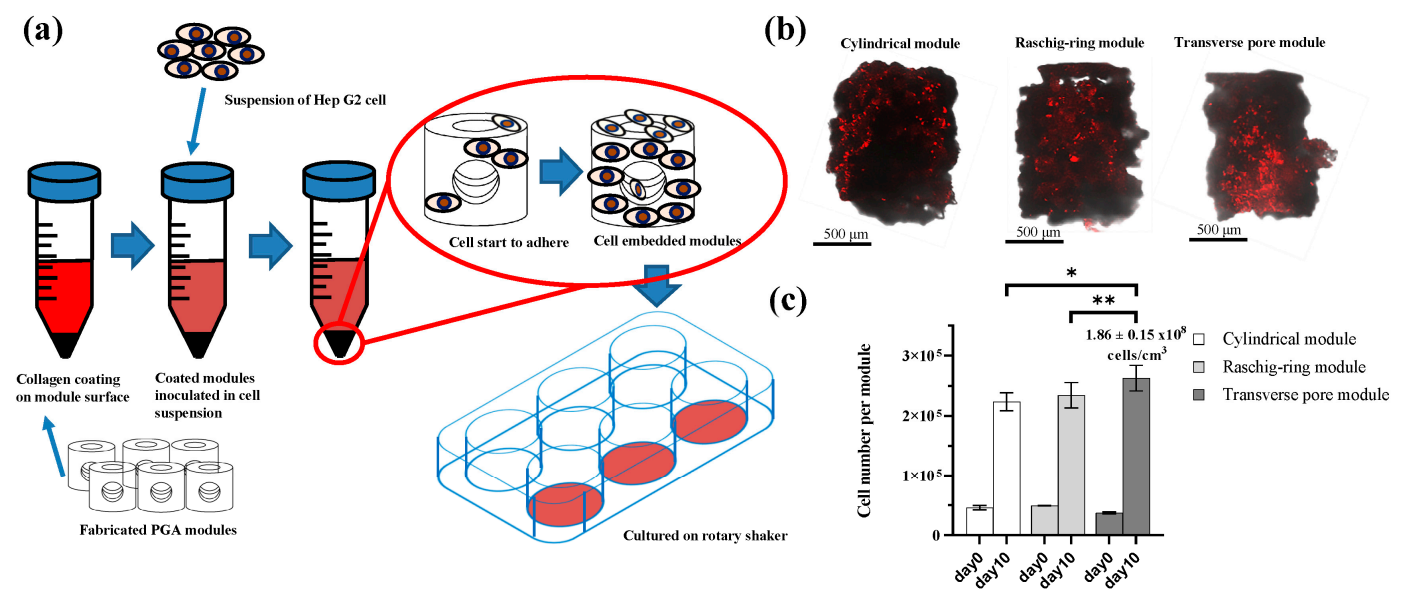

Figure 3. (a) Schematic illustration of cell inoculation. (b) Confocal images of immobilized human hematoma Hep G2 cells on Day 2 after inoculation. (c) Comparison of cell growth between different module types. Each point represents mean $\pm \mathrm{SD}\left(\mathrm{n}=2\right.$, independent experiments), ${ }^{*} P<0.05,{ }^{* *} P<0.01$.

Hep G2 cells were purchased from the Japanese Cancer Research Bank (JCRB) and routinely cultured in the above-mentioned modified high-glucose DMEM medium. Before inoculation, Hep G2 cells were labeled with fluorochrome PKH 26 (Sigma-Aldrich) and prepared into suspension. Collagen-coated modules were transferred into a $15 \mathrm{~mL}$ centrifuge tube containing $2 \times 10^{6} / \mathrm{mL}$ cell suspension and incubated at $37^{\circ} \mathrm{C}$ for $90 \mathrm{~min}$ with gentle shaking every $10 \mathrm{~min}$. After inoculation, cell-loaded modules were transferred to an untreated 6-well plate (15 modules in one well) on a rotary shaker at $144 \mathrm{rpm}$ for 10 days of culture at $37^{\circ} \mathrm{C}$ and $5 \% \mathrm{CO}_{2}$. The culture medium was replaced every day.

\subsection{DNA Content and Cellular-Function Measurement}

Immobilized cells successfully retained in the modules after the 10 days culture period were investigated. Modules loaded with cells were sonicated at $40 \mathrm{~W}$ for $1 \mathrm{~min}$ in an ice bath, and centrifuged at $600 \mathrm{rpm}$ for $5 \mathrm{~min}$ to separate the crushed PGA particles. The supernatant was measured by 4'.6-diamidino-2-phenylindole (DAPI) fluorometry to determine DNA content [8]. Glucose concentration in the sampled culture medium was quantified using a biochemistry analyzer (Glucose Analyze 2; Beckman Instruments, Galway, Ireland). Albumin secretion in the retrieved medium was measured by sandwich-type-enzyme-linked immunosorbent assay (ELISA) using antihuman albumin goat antibody (Cat A80-129A, Bethyl Products, Montgomery, TX, USA) and peroxidase-conjugated antihuman albumin goat antibody (Cat A80-129P, Bethyl Products, Montgomery, TX, USA) as the primary and secondary antibodies, respectively. Human serum albumin (ICN Pharmaceuticals, Cappel Products, Aurora, OH, USA) was used as the standard.

\subsection{Live Cell Evaluation after 10 Days of Culture}

After 10 days of culture, cell-loaded modules were carefully washed with PBS and then stained with calcein acetoxymethyl ester (calcein AM) to identify the live-cell condition. Staining was performed in accordance with a live/dead assay, which is a two-color fluorescence assay that simultaneously determines the number of live and dead cells. In the usual live/dead assay, the live cell is identified by cleaved calcein catalyzed by intracellular esterases that convert nonfluorescent, cell-permeable calcein AM to the intensely fluorescent calcein. Dead cells have damaged membranes, and ethidium 
homodimer-1 (EthD-1) enters the damaged cells and is fluorescent when bound to nucleic acids, after which EthD-1 produces bright red fluorescence in damaged or dead cells. In the present study, the cells were first marked with PKH 26 on the membrane before inoculation to modules. Therefore, the dead cells could not be identified by EthD-1 due to fluorescence from PKH 26. As a result, only calcein $\mathrm{AM}$ was used to localize the live cells after culture. Images were captured using confocal microscopy (FV 1000-D IX81, Olympus).

\subsection{Statistical Analysis}

Statistical analysis was performed by GraphPad Prism 8.2.1. Student's $t$-test was used to assess significant differences among the three types of modules. All data are presented as mean \pm standard deviation, and results with $P<0.05$ were considered significant.

\section{Results}

\subsection{PGA Module Fabrication}

Laser power for fabrication was carefully optimized to achieve a high filling factor. According to Table 1, with an increase of laser power, porosity showed an increasing trend. However, when the laser power exceeded 7.29 W, excessive energy caused the burn-through and burn-out phenomenon, which made the canal structure in the scaffold hard to maintain, and even collapse. Therefore, a power of 7.29 $\mathrm{W}$ was selected. The fabricated rectangular layers are shown in Figure 2a.

Table 1. Effects of laser power and wall thickness on filling factor.

\begin{tabular}{|c|c|c|c|c|}
\hline Power & $200 \mu \mathrm{m}$ & $300 \mu \mathrm{m}$ & $400 \mu \mathrm{m}$ & $500 \mu \mathrm{m}$ \\
\hline $2.86 \mathrm{~W}$ & Broken & Broken & Broken & Broken \\
\hline $4.14 \mathrm{~W}$ & Broken & Broken & Broken & Broken \\
\hline $5.27 \mathrm{~W}$ & $21.39 \%$ & $28.35 \%$ & $28.25 \%$ & $30.41 \%$ \\
\hline $6.25 \mathrm{~W}$ & $18.52 \%$ & $29.65 \%$ & $29.51 \%$ & $30.49 \%$ \\
\hline $7.29 \mathrm{~W}$ & $27.53 \%$ & $33.32 \%$ & $35.93 \%$ & $34.12 \%$ \\
\hline
\end{tabular}

Under the selected laser power, PGA layers ranging from 200 to $500 \mu \mathrm{m}$ were successfully fabricated. However, current modules were designed to have transverse pores on the side wall, and it was difficult to complete this structure with a $200 \mu \mathrm{m}$ thick side wall, which proved too fragile. Furthermore, due to the in vivo oxygen diffusion limitation of $200 \mu \mathrm{m}$ and flow supply provided from both the outer and inner wall surfaces, the wall of a hollow canal structure had a limiting thickness of $400 \mu \mathrm{m}$. Since the diameter of the laser beam caused the actual thin wall structure to be thicker than the designed size, a thickness of $300 \mu \mathrm{m}$ was selected for module fabrication.

Three types of fabricated PGA modules are shown in Figure 2b: solid cylinder (cylindrical module); cylinder with hollow through the center (Raschig ring module); and cylinder with hollow and canal placed perpendicularly towards the hollow on the side wall (transverse-pore module). The porosity of all modules was determined to be around $60 \%(n=15)$. The proposed design could be clearly distinguished on the top and side views for all modules.

\subsection{Evaluation of PGA Module Biodegradability}

Biodegradation of the PGA material was observed in raw powder and in the module structure without the presence of cells. Qualitatively, there was insignificant decrease in the molecular size of the powder, which was assumed to be bearable for mechanical stress during rotary culture. The fabricated modules were observed for deformation and degradation. As anticipated, the cylindrical, Raschig ring, and transverse-pore modules could withstand and maintain their rigidity. 
To examine the influence of degradation on the culture environment, $\mathrm{pH}$ changes were measured for determining the degradation rate, confirming the tendency of degradation instead of deformation related to mass-loss data. First, we tested degraded glycolic acid accumulation without replenishing culture medium. Following 10 days of culture in the medium, the $\mathrm{pH}$ of the three structures dropped to a minimum of 7.5 from an initial value of 7.7 , as shown in the Figure 4 . This did not cause cytotoxicity. The minimal $\mathrm{pH}$ after inoculating cells onto the module was higher than that obtained under the conditions without cells due to culture-medium replenishment.

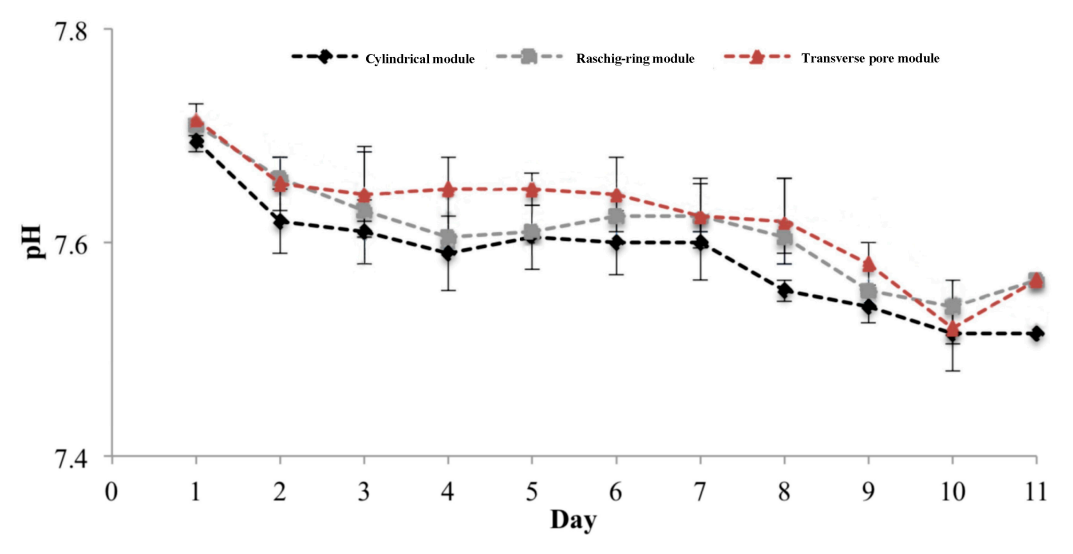

Figure 4. Changes in $\mathrm{pH}$ in three type of modules.

Deformation could occur as a result of biodegradation, leading to either structural cracks or powder transformation and further losses in rigidity. Including more hollow structures in the module design would improve fluidity and enhance exposure to the medium at gaps between the constructing PGA powder, which would result in a decrease in rigidity. Thus, we designed only one additional transverse canal that prevented structural destruction caused by biodegradation. Therefore, the modules designed in the present study fulfilled the mechanical and chemical requirements for further scaling up towards larger constructs.

\subsection{Cell Attachment}

After collagen coating and cell inoculation, confocal images confirmed the presence of immobilized Hep G2 cells in the modules within 2 days, as shown in Figure 3b. The quantity of cells inoculated within $1.5 \mathrm{~h}$ was estimated by DNA measurement. There were slightly more immobilized cells in the Raschig ring modules compared to the cylindrical and transverse-pore modules, as shown in Figure 3c.

Generally, including more canals in the module design would increase the surface area of the module for cell attachment. The immobilized cell number after $1.5 \mathrm{~h}$ of inoculation is shown in Figure $3 c$ as Day 0 data, with almost no significant differences between the three types of modules. This could be due to the fact that, during a short duration of $1.5 \mathrm{~h}$, the surface area of the modules was the main factor affecting the number of cells. Due to the existence of an additional radial canal, the outer surface area of the transverse-pore modules became smaller than that of the other module types, which accounted for a smaller number of immobilized cells (Figure 3c).

\subsection{Cell Growth after 10 Days of Suspension in Rotary Culture}

The number of final immobilized Hep G2 cells in the modules was measured on Day 10 of rotary culture by estimating DNA content. With increasing culture time, cells began to immobilize on both the inner and the outer surfaces. Differences in DNA content between cylindrical, Raschig ring-canal, and transverse-pore modules were significant, which showed that modules with more canals accommodated more cells (Figure 3c). On Day 10, about $2.62 \pm 0.22 \times 10^{5}$ cells $/$ module $\left(1.86 \pm 0.15 \times 10^{8} \mathrm{cells} / \mathrm{cm}^{3}\right.$ inside the module) were retained in the transverse-pore modules, which was 1.2 times higher than those in the cylindrical modules, and 1.1 times higher than those in the Raschig ring modules, equivalent to 
about $73 \%$ of in vivo tissue density [32]. Cell number in cylindrical, Raschig ring, and transverse-pore modules increased by $3.88 \pm 0.05,3.76 \pm 0.39$, and $5.89 \pm 0.07$ times, respectively, which indicated that better cellular growth was achieved by increased mass transfer and surface area with improved channel design.

As shown by the abundance of cells in the modules on Day 10 (Figure 5a), and compared to cell number in the initial cell inoculation (Figure $3 b$ ), cells continued to continuously grow during rotary culture. Furthermore, calcein AM staining was performed to distinguish cell viability and distribution in the different types of modules. It was evident that live cells produced different fluorescence intensity in the calcein AM-stained images, which indicated better cell viability in the transverse-pore modules as shown in Figure 5b. In addition, Hep G2 cells in the proposed design with channels showed more homogenous distribution.
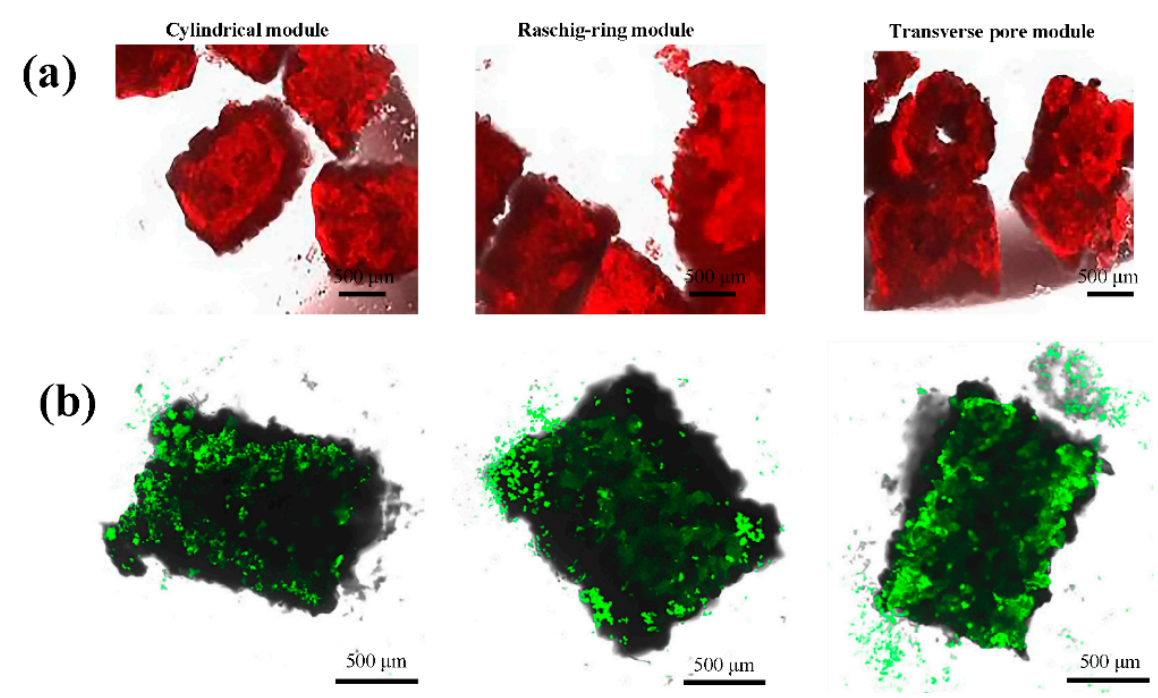

Figure 5. Confocal images of (a) PKH-labeled Hep G2 cells and (b) calcein AM-stained live cells on day 10 of culturing.

\subsection{Cellular Functions}

Glucose consumption by Hep G2 cells was determined and standardized by cell number in 10 day rotary cultures. As shown in Figure 6a, there was an irregular change on Day 3 that was probably caused by prolonged observation outside the incubator. The highest cellular glucose consumption per immobilized cell was observed in the transverse-pore module, and was found to be approximately 1.1 times higher than that in the cells in the cylindrical modules, and 1.2 times higher than that in the cells in the Raschig ring modules on Day 10. Albumin production by Hep G2 cells was also determined and standardized by cell number. As shown in Figure 6b, the detected albumin amount decreased steeply on Day 2 concurrently with decreased glucose consumption, but gradually increased during the remaining culture period. The highest albumin production in the 10 day culture was achieved by cells cultured in the transverse-pore modules, approximately being 1.6 times higher than that in cells in the cylindrical modules, and 1.2 times higher than in cells in the Raschig ring modules on Day 10, reinforcing the advantage of this module aside from the glucose-consumption aspect. 
(a)
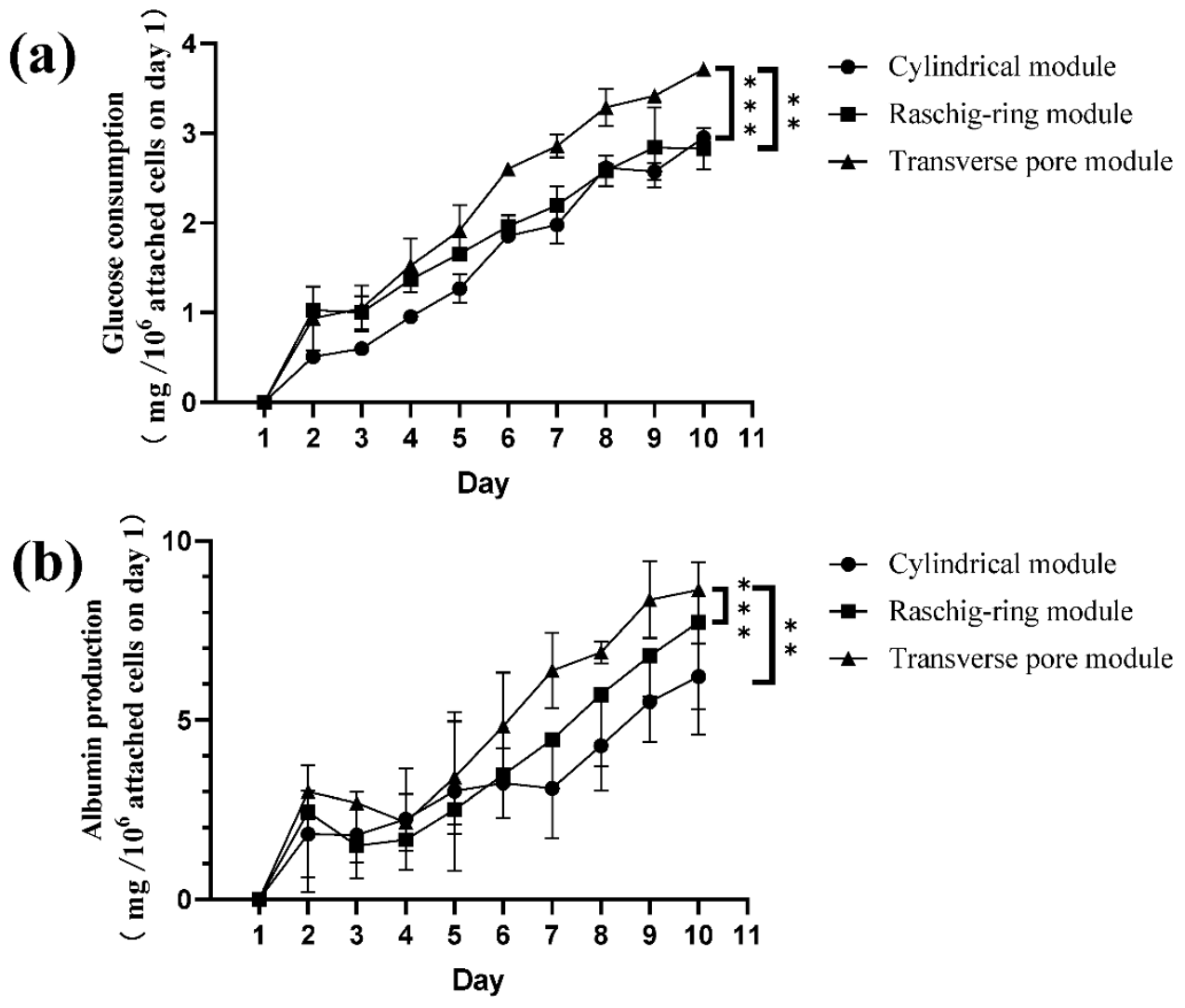

Figure 6. (a) Glucose consumption and (b) albumin production of Hep G2 cells in three types of modules. Each point represents mean $\pm \mathrm{SD}\left(\mathrm{n}=2\right.$ independent experiments). ${ }^{* *} P<0.01,{ }^{* * *} P<0.005$.

Significant differences in cellular function were observed between the cylindrical, Raschig ring, and transverse-pore modules. In line with the number of immobilized cells on Day 10, immobilized cells in the transverse-pore module showed better cell function and higher viability than those in other models, which was also reinforced by the qualitative results from the viability assay through images obtained by confocal microscopy. Given the fact that albumin secretion is sensitive to oxygen concentration, this result indicated that the provided hollow structures improved mass transfer [33].

\section{Conclusions}

In the present study, we designed modules on the basis of the Raschig ring as tissue elements fabricated with a modified SLS method. The selected material, PGA, possessed optimal mechanical strength under dynamic-flow conditions with bearable shape deformation and suitable biodegradation rate without producing an acidic environment. As a building block, the PGA module based on Raschig ring design accommodated more cells than the ordinary cylinder module due to the existence of canals, and provided optimal cell attachment with a collagen coating. After 10 days of culture, the proposed module design showed higher viability, glucose consumption, and albumin production, and improvement in mass transfer in a rotary-culture model. However, due to manufacturing limitations, it was not confirmed if more than two flow channels could further promote hepatic functions, and the topological structure design of the modules was not analyzed in the study. Future studies should focus on the optimization of the scaffold structure, which holds great potential in bottom-up tissue engineering.

Author Contributions: Conceptualization, design, and experiments, J.J., Y.P., and S.S.; module fabrication: Y.H.; provision of study materials: Y.P., T.N., and Y.S.; administrative support: W.S., T.N., and Y.S.; manuscript writing and final approval of manuscript, all authors. All authors have read and agreed to the published version of the manuscript. 
Funding: This work was supported by the National Natural Science Foundation of China (51805294), Tsinghua University Initiative Scientific Research Program (20193080045 and 20197050024), the National Key Research and Development Program of China (2018YFA0703004), and the 111 Project ( B17026).

Conflicts of Interest: The authors declare no conflict of interest.

\section{References}

1. Pang, Y.; Sutoko, S.L.U.; Horimoto, Y.; Anzai, M.; Niino, T.; Sakai, Y. An insight into in vitro construction of implantable liver: From "bottom up" integrated with "top down" aspects. SEISAN KENKYU 2015, 67, $259-264$.

2. Nichol, J.W.; Khademhosseini, A. Modular tissue engineering: Engineering biological tissues from the bottom up. Soft Matter 2009, 5, 1312-1319. [CrossRef] [PubMed]

3. Skylar-Scott, M.A.; Uzel, S.G.M.; Nam, L.L.; Ahrens, J.H.; Truby, R.L.; Damaraju, S.; Lewis, J.A. Biomanufacturing of organ-specific tissues with high cellular density and embedded vascular channels. Sci. Adv. 2019, 5, eaaw2459. [CrossRef]

4. Han, H.W.; Asano, S.; Hsu, S.H. Cellular spheroids of mesenchymal stem cells and their perspectives in future healthcare. Appl. Sci. 2019, 9, 627. [CrossRef]

5. Douglas, W.H.J.; McAteer, J.A.; Dell'orco, R.T.; Phelps, D. Visualization of cellular aggregates cultured on a three dimensional collagen sponge matrix. In Vitro 1980, 16, 306-312. [CrossRef] [PubMed]

6. Schon, B.S.; Hooper, G.J.; Woodfield, T.B.F. Modular Tissue Assembly Strategies for Biofabrication of Engineered Cartilage. Ann. Biomed. Eng. 2017, 45, 100-114. [CrossRef]

7. Carmeliet, P.; Jain, R.K. Angiogenesis in cancer and other diseases. Nature 2000, 407, 249-257. [CrossRef]

8. Griffith, C.K.; Miller, C.; Sainson, R.C.A.; Calvert, J.W.; Jeon, N.L.; Hughes, C.C.W.; George, S.C. Diffusion limits of an in vitro thick prevascularized tissue. Tissue Eng. 2005, 11, 257-266. [CrossRef]

9. Kang, H.W.; Lee, S.J.; Ko, I.K.; Kengla, C.; Yoo, J.J.; Atala, A. A 3D bioprinting system to produce human-scale tissue constructs with structural integrity. Nat. Biotechnol. 2016, 34, 312-319. [CrossRef]

10. Mizumoto, H.; Hayashi, S.; Matsumoto, K.; Ikeda, K.; Kusumi, T.; Inamori, M.; Nakazawa, K.; Ijima, H.; Funatsu, K.; Kajiwara, T. Evaluation of a hybrid artificial liver module based on a spheroid culture system of embryonic stem cell-derived hepatic cells. Cell Transplant. 2012, 21, 421-428. [CrossRef]

11. Pang, Y.; Montagne, K.; Shinohara, M.; Komori, K.; Sakai, Y. Liver tissue engineering based on aggregate assembly: Efficient formation of endothelialized rat hepatocyte aggregates and their immobilization with biodegradable fibres. Biofabrication 2012, 4, 045004. [CrossRef] [PubMed]

12. Wolint, P.; Bopp, A.; Woloszyk, A.; Tian, Y.; Evrova, O.; Hilbe, M.; Giovanoli, P.; Calcagni, M.; Hoerstrup, S.P.; Buschmann, J.; et al. Cellular self-assembly into 3D microtissues enhances the angiogenic activity and functional neovascularization capacity of human cardiopoietic stem cells. Angiogenesis 2019, 22, 37-52. [CrossRef]

13. Swinehart, I.T.; Badylak, S.F. Extracellular matrix bioscaffolds in tissue remodeling and morphogenesis. Dev. Dyn. 2016, 245, 351-360. [CrossRef] [PubMed]

14. Wang, S.; Sekiguchi, R.; Daley, W.P.; Yamada, K.M. Patterned cell and matrix dynamics in branching morphogenesis. J. Cell Biol. 2017, 216, 559-570. [CrossRef] [PubMed]

15. Kelm, J.M.; Djonov, V.; Ittner, L.M.; Fluri, D.; Born, W.; Hoerstrup, S.P.; Fussenegger, M. Design of custom-shaped vascularized tissues using microtissue spheroids as minimal building units. Tissue Eng. 2006, 12, 2151-2160. [CrossRef] [PubMed]

16. Unger, R.E.; Ghanaati, S.; Orth, C.; Sartoris, A.; Barbeck, M.; Halstenberg, S.; Motta, A.; Migliaresi, C.; Kirkpatrick, C.J. The rapid anastomosis between prevascularized networks on silk fibroin scaffolds generated in vitro with cocultures of human microvascular endothelial and osteoblast cells and the host vasculature. Biomaterials 2010, 31, 6959-6967. [CrossRef]

17. Norotte, C.; Marga, F.S.; Niklason, L.E.; Forgacs, G. Scaffold-free vascular tissue engineering using bioprinting. Biomaterials 2009, 30, 5910-5917. [CrossRef]

18. Laschke, M.W.; Menger, M.D. Prevascularization in tissue engineering: Current concepts and future directions. Biotechnol. Adv. 2016, 34, 112-121. [CrossRef]

19. Frueh, F.S.; Menger, M.D.; Lindenblatt, N.; Giovanoli, P.; Laschke, M.W. Current and emerging vascularization strategies in skin tissue engineering. Crit. Rev. Biotechnol. 2017, 37, 613-625. [CrossRef] 
20. Versteegden, L.R.M.; de Jonge, P.K.J.D.; IntHout, J.; van Kuppevelt, T.H.; Oosterwijk, E.; Feitz, W.F.J.; de Vries, R.B.M.; Daamen, W.F. Tissue Engineering of the Urethra: A Systematic Review and Meta-analysis of Preclinical and Clinical Studies [Figure presented]. Eur. Urol. 2017, 72, 594-606. [CrossRef]

21. Rossi, G.; Manfrin, A.; Lutolf, M.P. Progress and potential in organoid research. Nat. Rev. Genet. 2018, 19, 671-687. [CrossRef] [PubMed]

22. Pasca, S.P. Assembling human brain organoids. Science (80-) 2019, 363, 126-127. [CrossRef] [PubMed]

23. Shah, S.B.; Singh, A. Cellular self-assembly and biomaterials-based organoid models of development and diseases. Acta Biomater. 2017, 53, 29-45. [CrossRef] [PubMed]

24. McGuigan, A.P.; Leung, B.; Sefton, M.V. Fabrication of cells containing gel modules to assemble modular tissue-engineered constructs. Nat. Protoc. 2007, 1, 2963-2969. [CrossRef]

25. Mamaliga, I.; Sidor, D.; Condurat, C.; Iacob Tudose, E.T. Hydrodynamics and mass transfer coefficients for a modified Raschig ring packed column. Heat Mass Transf. Stoffuebertrag. 2014, 50, 1385-1392. [CrossRef]

26. Terakawa, M. Femtosecond laser processing of biodegradable polymers. Appl. Sci. 2018, 8, 1123. [CrossRef]

27. Alhnan, M.A.; Okwuosa, T.C.; Sadia, M.; Wan, K.W.; Ahmed, W.; Arafat, B. Emergence of 3D Printed Dosage Forms: Opportunities and Challenges. Pharm. Res. 2016, 33, 1817-1832. [CrossRef]

28. Ginde, R.M.; Gupta, R.K. In vitro chemical degradation of poly(glycolic acid) pellets and fibers. J. Appl. Polym. Sci. 1987, 33, 2411-2429. [CrossRef]

29. Mooney, D.J.; Mazzoni, C.L.; Breuer, C.; McNamara, K.; Hern, D.; Vacanti, J.P.; Langer, R. Stabilized polyglycolic acid fibre-based tubes for tissue engineering. Biomater. Silver Jubil. Compend. 1996, 17, $129-138$.

30. Pang, Y.; Sutoko, S.; Horimoto, Y.; Weng, D.; Montagne, K.; Komori, K.; Takano, K.; Shirakashi, R.; Anzai, M.; Niino, T.; et al. Biodegradable and hollowed micro-scaffolds for improved modular assembly-based tissue engineering: Design, 3D fabrication, and feasibility in randomly packed perfusion culture. Biochem. Eng. J. 2019, 149, 107239. [CrossRef]

31. Watanabe, M.; Fujioka-Kaneko, Y.; Kobayashi, H.; Kiniwa, M.; Kuwano, M.; Basaki, Y. Involvement of integrin-linked kinase in capillary/tube-like network formation of human vascular endothelial cells. Biol. Proced. Online 2005, 7, 41-47. [CrossRef] [PubMed]

32. Sakai, Y.; Huang, H.; Hanada, S.; Niino, T. Toward engineering of vascularized three-dimensional liver tissue equivalents possessing a clinically significant mass. Biochem. Eng. J. 2010, 48, 348-361. [CrossRef]

33. Pang, Y.; Sutoko, S.; Wang, Z.; Horimoto, Y.; Montagne, K.; Horiguchi, I.; Shinohara, M.; Danoy, M.; Niino, T.; Sakai, Y. Organization of liver organoids using Raschig ring-like micro-scaffolds and triple co-culture: Toward modular assembly-based scalable liver tissue engineering. Med. Eng. Phys. 2020, 76, 69-78. [CrossRef] [PubMed]

(C) 2020 by the authors. Licensee MDPI, Basel, Switzerland. This article is an open access article distributed under the terms and conditions of the Creative Commons Attribution (CC BY) license (http://creativecommons.org/licenses/by/4.0/). 